\title{
Social and Family Factors as Determinants of Exercise Habits in Japanese Elementary School Children: The Super Shokuiku School Project
}

\section{Satomi Sawa ( $\sim$ sawa@edu.u-toyama.ac.jp )}

Toyama Daigaku https://orcid.org/0000-0002-9284-6438

\section{Michikazu Sekine}

Toyama Daigaku Igakubu Daigakuin Igaku Yakugaku Kyoikubu

\section{Masaki Yamada}

Toyama Daigaku Igakubu Daigakuin Igaku Yakugaku Kyoikubu

\section{Yugo Fukazawa}

Fukui Daigaku

\section{Yusuke Hiraku}

Fukui Daigaku

Research article

Keywords: elementary-school children, physical activity, parental lifestyle, social background

Posted Date: October 15th, 2019

DOI: https://doi.org/10.21203/rs.2.16087/v1

License: (9) This work is licensed under a Creative Commons Attribution 4.0 International License. Read Full License 


\section{Abstract}

Background Many studies have already reported on the relationship between exercise habits and health among schoolchildren. However, few have examined social and/or family factors as determinants of exercise habits. This study investigated factors related to both dislike and lack of physical activity among schoolchildren. Methods This study's participants included 1,984 school children (1,001 boys and 983 girls) aged between 6 and 13 from the Super Shokuiku School Project in January 2016. A survey was conducted to assess sex, grade level, physical activity, lifestyle, overall health, enrichment of school life, social background, and parental lifestyles. Both the dislike and lack of physical activity were defined as poor exercise habits; correlates were analyzed using a logistic regression. Results "Lack of close friends" had the strongest links with both dislike (adjusted odds ratio [OR] 5.30; 95\% confidence interval [Cl], 2.7810.1) and lack of (adjusted OR 5.40; 95\%Cl, 2.81-10.4) physical activity. Further, children who engaged in long periods of screen time and lacked parental communication also tended to dislike and lack physical activity. Children with mothers who were unemployed (housewife) and had undesirable lifestyles as well as those with poor health were also more likely to lack physical activity. Conclusion Social and family factors (e.g., close friends) may be determinants of exercise habits among schoolchildren independently of their own lifestyle factors. Although a longitudinal study is needed to determine causality, substantial attention should thus be paid to these factors when promoting physical activity.

\section{Background}

The Physical and Athletic Aptitude Survey [1] conducted by the Japanese Ministry of Education, Culture, Sports, Science and Technology (MEXT) indicates that there is a widening physical ability gap between children who engage in physical activity and those who do not [2]. Moreover, the number of children who do not exercise increases with age [3]. Such reductions may be associated with lower levels of motivation, emotional strength, and the ability to form interpersonal relationships. Unfortunately, these problems may also negatively influence psychosocial development [4]. The Japan Sports Agency has thus proposed a goal of increasing the rate of sports participation from $58.7 \%$ to $80 \%$ while decreasing the percentage of junior high school students who dislike sports from $16.4 \%$ to $8 \%$ by the year 2022 [5]. As such, it is important to research the reasons for the growing lack of physical activity and sedentary lifestyles among these children to determine what measures are needed to develop good exercise habits during early childhood.

Children are now spending less time playing outside and/or participating in sports. By contrast, they are spending longer hours indoors while watching television and playing games. Many studies have linked such physical inactivity to overweightness and obesity [6], peer problems [7], and school-avoidant emotions [8]. Further, children with overweight or obese mothers tend to engage in less physical activity and spend more time watching television and playing games [9]. Similarly, children who are in poorer health and have parents that are heavy internet users tend to engage in longer screen times [10]. These conditions provide evidence that child health is significantly influenced by health-related parental behavior [9-11]. On the other hand, studies have reported that even short durations of physical activity 
effectively reduce anxiety and/or boost self-esteem [7], while consistent physical activity can help mitigate emotional problems [12]. Moreover, elementary schools that successfully reduced the rate of child inactivity were also able to increase the number of students who enjoyed such engagement [13]. This indicates that physical activity can be encouraged through enjoyment, thus promoting wholesome physical and mental health while providing fulfilling school experiences.

Meanwhile, Japan has one of the highest rates of child poverty among all Organisation for Economic Cooperation and Development (OECD) nations. In this context, widening socioeconomic disparities and their effects on child health are serious concerns $[14,15]$. As such, health education should be mandatory in the school setting for both parents and children regardless of academic achievement [14] or socioeconomic status [14-17]. These measures are now highly anticipated. Notably, previous studies have reported that lifestyle is a major influencing factor for children who dislike and lack physical activity $[18,19]$. However, few studies have examined how these factors are related to the family environment and other social factors surrounding the child. This study therefore comprehensively investigated the factors related to both the dislike and lack of physical activity among children, including habits that relate to health and lifestyle, the family environment, and other social factors.

\section{Methods}

\section{(1) Participants and the survey outline}

A total of 2,129 children aged between 6 and 13 from the Super Shokuiku School Project (Phase 3: January 2016) $[10,20]$ and who belonged to one of five elementary schools in Takaoka City, Japan participated in this study. The Super Shokuiku School Project was designed to investigate food education and was supported by the Japanese Ministry of Education, Culture, Sports, Science and Technology (MEXT). The overall purpose of the project was to promote healthy lifestyles in school children and improve their health. The survey was approved by the Ethics Committee of University of Toyama. Written informed consent was obtained from the participants' parents, and participation was voluntary.

\section{(2) Questionnaire}

Participants were asked to complete questionnaires asking about sex, grade level, physical activity, lifestyle, overall health, enrichment of school life, social background, and parental lifestyles. The children responded with their parents if necessary. The child responded to items concerning sex, grade, physical activity, lifestyle, overall health, and enrichment of school life by themselves, while their parents responded to items concerning social background and parental lifestyles. All completed questionnaire were returned to the respective schools of each participant. 


\section{Physical Activity}

The physical activity portions of the questionnaire included the items of "frequency of physical activity" [21] and "preference for physical activity." [18] Responses to "frequency of activity" were answered according to a 4-point scale and divided into the two following categories: "Very often (very often, often)" or "Not often (rarely, almost never)." Responses to "preference for physical activity" were also answered according to a 4-point scale, and were divided into the two following categories: "Like very much (like very much, like)" or "Dislike (don't like so much, dislike)." Validity for both these items had already been determined by a previous study [21]. In this context, a high frequency of physical activity was significantly associated with an increasing trend in energy expenditure originating from physical activity.

\section{Social background and parental lifestyles}

Social background was assessed based on the following items: Mother's employment status, family structure, perceived family affluence, communication with parents, individual parental internet usage at home h/day (i.e., both the mother and father), and parental health behaviors according to Breslow (1980) (i.e., both the mother and father). The item concerning "mother's employment status" $[20,22]$ included three response categories (i.e., "full-time," "part-time," and "unemployed (housewife)"), while "family structure" [22,23] was categorized as either "three-generation family" or "nuclear family." Further, "socioeconomic status" was determined according to perceived "family affluence" [20,22] (i.e., "affluent," "neither," or "not affluent"), while "communication with parents" [22,24] was categorized as either "often" or "rarely." We also asked for the total time parents spent using the internet at home h/day. Here, responses were given according to a 6-point scale and divided into the two categories of " $<2 \mathrm{hr}$ (no or almost none, $<1 \mathrm{hr}$, and $1 \mathrm{hr}$ to $<2 \mathrm{hr}$ )" and " $\geqq 2 \mathrm{hr}$ ( $2 \mathrm{hr}$ to $<3 \mathrm{~h}$, and $\geq 3 \mathrm{hr}$ )." This was based on a 2018 report indicating that Japanese adults in their 30 s spent an average of about 1.5 hours per day on the internet $[10,25]$. Breslow's (1980) seven good health-related behaviors have been widely accepted for use in Westernized countries, and were thus used as parental health indicators in this study [26]. The behaviors include (1) adequate sleep time, (2) no smoking, (3) appropriate weight control, (4) not drinking excessively, (5) regular physical activity, (6) no skipping of breakfast, and (7) not frequently snacking. We divided respondents into three groups based on their indicated number of behaviors (i.e., "low (0-3)," "middle (4-5)," and "high (6-7)"); higher numbers indicated healthier behaviors.

\section{Child lifestyle factors}

Child lifestyles were assessed based on breakfast consumption, wake-up time, bedtime, nighttime sleep duration, screen time h/day, and cram schools after school. Here, "breakfast consumption" $[10,27]$ was classified into the two categories of "eat every day" and "skipping," while "wake up time" [23] was classified into the three categories of "before 06:30," "06:30-07:00," and "after 07:00." Further, "bedtime" 
[23] was classified into the three categories of "before22:00," "22:00-23:00," and "after23:00," while "nighttime sleep duration" [23] was categorized according to the number of sleeping hours (i.e., "more than 8 hours" and "less than 8 hours"). This was based on previous research indicating that Japanese elementary school children average approximately 8.5 hours of sleep per night [25].

The question about "screen time h/day" for children included television and film viewing, gaming, and internet use[20]. Here, responses were given according to a 6-point scale and divided into the two categories of " $<2 h$ (no, almost none, $<1 h$, and $<2 h$ )" and " $\geqq 2 h$ ( $<3 h, 3$ to $<4 h$, and $\geqq 4 h$ )." In this context, the Japan Pediatric Association recommends that total screen time be limited to $<2 \mathrm{~h}$ per day[25].

\section{Overall health among child participants}

A question from a validated Japanese version of the Dartmouth Primary Care Cooperative Information Project (COOP) was used to evaluate overall health among children $[18,19,28]$. They were specifically asked the following: "During the past 4 weeks, how would you rate your physical and mental health in general?" Subjects who rated their overall health as "excellent," "very good," or "good" were classified as having "good health status," while those who answered "fair" or "poor" were classified as having "poor health status."

\section{Enrichment of school life}

We asked two questions to subjectively assess "enrichment of school life," including "Do you have close friends?" [29] and "Are you able to understand school lessons well?" [20] Responses were given according to 4 and 5-point scales, respectively, and then divided into the following respective categories for each question: "yes (many, a few)" or "no (not many, no friends)" and "understand well (well, relatively well)" or " do not understand (neither, relatively poor, and poor)."

\section{(3) Statistical analyses}

Logistic regression analyses were conducted to evaluate the strengths of the associations between child physical activity and the items of social background, parental lifestyles, child lifestyles, child health, and enrichment of school life. All variables were simultaneously entered into the model during multivariate analyses. Odds ratios (ORs) and 95\% confidence intervals (Cls) were also calculated. Finally, logistic regression analyses were performed to determine the strengths of the associations between "lack of physical activity" regardless of "prefer physical activity" with the items of social background, parental lifestyles, child lifestyles, overall child health, and enrichment of school life. All analyses were conducted 
using the statistical package for social scientists (SPSS) software version $22.0 \mathrm{~J}$ (SPSS, Chicago, IL, USA). Two-tailed $P$-values less than 0.05 were considered statistically significant for all tests.

\section{Results}

Participant characteristics are shown in Table 1. Of the 2,129 respondents who returned their questionnaires, 1,984 (1,001 boys and 983 girls) answered all relevant items and were thus included for analysis. Regarding child physical activity, $13.2 \%$ of respondents $(n=260)$ did not like physical activity, while $27.4 \%(n=540)$ lacked physical activity. Regarding social background factors, the most frequent answers to the items assessing the mother's employment status, family structure, and perceived family affluence were "part time," "nuclear family," and "neither," respectively. Regarding parental lifestyles, the most frequent answers to the questions assessing parental internet use at home were " $<2 \mathrm{~h}$, and parental (e.g., mother and father) health behaviors according to Breslow (1980) [26] were "father is low," and "mother is middle," respectively.

The results of the logistic regression analyses conducted to determine the strengths of the associations between "do not like physical activity" and social background, parental lifestyles, child lifestyles, overall child health, and enrichment of school life are available in Table 2. The multivariate analysis revealed the following results: "do not like physical activity" for children in middle grades (3rd and 4th graders, ages 810) (adjusted OR, 2.39; 95\% Cl, 1.59-3.58), high grades (5th and 6th graders, ages 11-12) (adjusted OR $2.73 ; 95 \% \mathrm{Cl}, 1.83-4.08$ ), poor communication with parents (adjusted OR 1.57; $95 \% \mathrm{Cl}, 1.10-2.25$ ), long screen times of child (adjusted OR 1.38; 95\% Cl, 1.02-1.87), and do not have close friends (adjusted OR $5.30 ; 95 \% \mathrm{Cl}, 2.78-10.1)$.

The results of the logistic regression analyses conducted to determine the strengths of the associations between "lack of physical activity" and social background, parental lifestyles, child lifestyles, overall child health, and enrichment of school life are available in Table 3. The multivariate analyses revealed the following: girls (adjusted OR 1.40; 95\% Cl,1.11-1.76), middle grades (3rd and 4th graders, ages 8-10) (adjusted OR 1.53; 95\% Cl, 1.15-2.04), high grades (5th and 6th graders, ages 11-12) (adjusted OR 1.82; $95 \% \mathrm{Cl}, 1.37-2.42$ ), unemployed mother (housewife) (adjusted OR 1.92; 95\% Cl, 1.37-2.68), poor communication with parents (adjusted OR 1.59; 95\% Cl,1.19-2.13), mothers with middle health behaviors (adjusted OR 1.50; 95\% Cl, 1.13-1.99), mothers with low health behaviors (adjusted OR 1.53; 95\% Cl, 1.072.20), long screen times of child (adjusted OR $1.47 ; 95 \% \mathrm{Cl}, 1.17-1.86)$, bad overall health (adjusted OR $1.66 ; 95 \% \mathrm{Cl}, 1.12-2.47$ ), and do not have close friends (adjusted OR 5.40; $95 \% \mathrm{Cl}, 2.81-10.4$ ) were associated with "lack of physical activity."

While children who lacked physical activity comprised $27.4 \%$ of the total, more than half said that they did prefer physical activity. However, many still did not engage in physical activity. The logistic regression analysis results conducted to determine the strengths of the associations between "lack of physical activity" regardless of "prefer physical activity" and social background, parental lifestyles, child lifestyles, overall child health, and enrichment of school life are available in Table 4. The multivariate analyses 
revealed that girls (adjusted OR 1.52; 95\%Cl, 1.13-2.04), unemployed mothers (housewife) (adjusted OR 2.30; $95 \% \mathrm{Cl}, 1.52-3.47$ ), poor communication with parents (adjusted OR 1.50; 95\% Cl, 1.03-2.19), mothers with middle health behaviors (adjusted OR $1.55 ; 95 \% \mathrm{Cl}, 1.08-2.24$ ), long screen times of child (adjusted OR 1.54; 95\% Cl, 1.15-2.08), and those without close friends (OR 4.14; $95 \% \mathrm{Cl}, 1.80-9.51$ ) were associated with "lack of physical activity" regardless of "prefer physical activity."

\section{Discussion}

Among the potential determinants of child exercise habits, this study revealed that a lack of close friends was likely the most influential factor for both disliking and lacking physical activity. Further, the status of having close friends was independently associated with child exercise habits even after adjusting for other potential confounding factors, the social and family environment, and child lifestyle factors. Previous studies have already shown that peer support is important for promoting exercise habits [7], while the presence of friends promotes activeness [30] and reduces the time spent sitting [31]. These results have important implications for educational policies, behavioral practices, and future research.

While children with depression often have problems in their relationships with friends and peers [24], increasing the level physical activity can help reduce these issues [7]. Our findings showed that child mental and physical health conditions were linked to their exercise habits. Specifically, children with screen times of $\geq 2$ hours per day were more likely to dislike and lack physical activity when compared to those with screen times of less than 2 hours. In this context, internet addiction and gaming disorders are both recognized as diseases by the World Health Organization [32]. Recent surveys have also highlighted that these disorders especially affect young children and that experiences related to physical activity and increased peer communication are effective for prevention and treatment [33]. Offline interactions between children are increasingly becoming scarce. As such, approaches to ensure sound childhood relationships are essential educational goals [34].

Previous studies have also noted that poor childhood exercise habits are common in low-income families [35]. However, this study found other family-related factors that influenced the dislike and lack of physical activity, including the presence of stay-at-home mothers, unhealthy parental lifestyles, and infrequent communication with parents; children in these conditions were more often sedentary despite answering that they liked physical activity. The odds ratios for mothers of children who preferred physical activity but lacked engagement and who were full-time housewives were higher than that of children who simply lacked physical activity. This suggests that childhood exercise habits may be influenced by maternal lifestyles and that children may be deficient in physical activity due to social and family factors even when they like physical activity. Previous studies have shown that families lacking in parent-child communication were more sedentary and had lower health satisfaction [22]. Conversely, children who frequently talked with their parents had better bowel movements, thus indicating proper digestion [24]. Further, children develop an attachment to their parents through physical touch and communication [36]. Accordingly, healthy parent-child communication is essential for childhood mental and physical health as well as the development of healthy exercise habits. Previous studies have also reported that longer screen 
times, later bedtimes, and poorer lifestyle habits were more common among children with mothers with who worked full time. However, such evidence is inconclusive; more recent studies have shown that children with mothers who worked full time had higher levels of physical activity [9], thus suggesting they were less affected by maternal employment status [24]. This study's results further support the idea that maternal employment status and/or the way children spend their after-school hours have changed over time. For example, afterschool clubs and services are now available [37] for children whose parents or legal guardians are away from home during the initial after-school hours. This is partially the result of the Act on the Promotion of Female Participation and Career Advancement in the Workplace, which was passed in August 2015. Further, a 2017 survey [38] indicated that such afterschool clubs provide space for and promote physical activity. It is therefore possible that children with working mothers are able to engage in physical activity outside the home. As previous studies have shown [31], childhood sedentary behaviors can be substantially reduced by providing support and increasing the parental awareness about the importance of exercising. As such, it is highly important to provide environments that are conducive to physical activity during afterschool hours and on weekends.

Children with mothers who have unhealthy habits also tend to have sedentary lifestyles despite liking physical activity. Other studies using similar indicators have shown that children with parents who have unhealthy lifestyles were more likely to have sedentary lifestyles and eat meals alone [22]. The UNICEF Report Card on Child-Wellbeing in a Sustainable World [39] also suggested that family relationships were the most important factors for childhood wellbeing, followed by friends and school. Perhaps the importance of close friends and family communication for developing good exercising habits as found in this study reflect the "wellness" that children in developed countries experience. It is clear that increased communication and common health awareness are needed to promote good exercise habits in children.

This study had several limitations. First, it used a cross-sectional design that employed a self-reported survey about exercising habits. Thus, a longitudinal survey is needed to investigate the causal relationships behind these results to measure both the quality and quantity of physical activity through objective indicators. Second, more detailed surveys on social context (e.g., community characteristics, maternal employment status, and social assistance) are required to investigate the measures that are best-suited for community-specific needs.

This study found that a fulfilling school life, family environment, parental lifestyle-related habits, and the activities of the children themselves were factors that influenced childhood exercise habits. This indicates that educational policies and interventions should consider linking these items to healthy exercise habits.

Ideal childhood exercise habits are most effectively promoted through the establishment of a fulfilling school life. Thus, related initiatives should encourage children to develop close friendships through physical activity at lower grade levels. Home-life is also important. Changes to both afterschool activities and those on the weekends can be improved by promoting shorter screen times, better parental lifestyles, and improved parent-child communication. Collectively, these efforts will lead to better childhood exercise habits. Finally, communities and schools should cooperate to build safe environments and spaces in 
which children can freely and securely engage in physical activity regardless of their parents' employment status or home environments.

\section{Conclusions}

This study investigated factors related to both dislike and lack of physical activity among schoolchildren as part of The Super Shokuiku School Project in Japan. "Lack of close friends" have the strongest links with both dislike and lack of physical activity. Children who engaged in long periods of screen time and lacked parental communication also tended to dislike and lack physical activity. In addition, children were highly influenced by parental lifestyles, even those who like physical activity. Although a longitudinal study is needed to determine causality, substantial attention should thus be paid to these factors when promoting physical activity.

\section{Declarations}

\section{Acknowledgements}

We thank all children and their guardians for participating in this study. We also thank Toyama Prefecture and Takaoka City Education Committee, as well as the principals and school nurses at five elementary schools Takaoka city, Toyama prefecture, who agreed to take part in this study.

This study was funded through the Super Shokuiku School Project by the Ministry of Education, Culture, Sports, Science and Technology, Japan.

\section{Authors' Contributions}

S.S conceptualized and designed the study, carried out statistical analysis, drafted the initial manuscript, and reviewed and revised manuscript. M.S, M.Y obtained the fund, designed the study, collected data, and critically reviewed the manuscript. Y.F, Y.H critically reviewed the manuscript. All authors approved the final manuscript as submitted and agreed to be accountable for all aspects of the work.

\section{Funding}

No funding.

\section{Availability of data and materials}

The data we used to derive our findings are unsuitable for public deposition due to ethical restrictions and specific legal framework in Japan. It is prohibited by the Act on the Protection of Personal Information (Act No.57 of 30 May 2003, amended on 9 September 2015) to publicly deposit data containing personal information. The Ethical Guidelines for Epidemiological Research enforced by the Japan Ministry of 
Education, Culture, Sports, Science, and Technology and the Ministry of health, Labor and Welfare also restrict the open sharing of the epidemiologic data.

\section{Ethics approval and consent to participate}

The survey was approved by Ethics Committee of University of Toyama (H28-137). Written informed consent was obtained from all the school children and their parents, and participation was voluntary.

\section{Consent for publication}

Not applicable.

\section{Competing interests}

The authors declare that they have no competing interests.

\section{References}

1. Ministry of Education, Culture, Sports, Science and Technology. New Strength Test, for Meaningful Use. Tokyo, Japan: Gyosei; 2000. (in Japanese)

2. Ishii K, Shibata A, Adachi M, Mano Y, Oka, K. Objectively measured sedentary behavior, obesity, and psychological well-being: A cross-sectional study of Japanese schoolchildren. J Phys Act Health. 2017;14(4):270-274. doi:10.1123/jpah.2016-0374.

3. Sasagawa Sports Foundation. The 2015 SSF National Sports-Life Survey of Young People. Tokyo, Japan: Nihon Publicity Co., Ltd; 2015. (in Japanese)

4. Ministry of Education, Culture, Sports, Science and Technology. Infantile movement guideline guidebook. http://www.mext.go.jp/a_menu/sports/undousisin/1319772.htm; Accessed 13 Jul 2019. (in Japanese)

5. Japan Sports Agency. Sports Basic Plan. http://www.mext.go.jp/sports/b_menu/sports/mcatetop01/list/1372413.htm; Accessed 27 Jul 2019. (in Japanese)

6. Vilchis-Gil J, Galván-Portillo M, Klünder-Klünder M, Cruz M, Flores-Huerta. Food habits, physical activities and sedentary lifestyles of eutrophic and obese school children: A case-control study. BMC Public Health. 2015;15:124. doi:10.1186/s12889-015-1491-1.

7. Ahn JV, Sera F, Cummins S, Flouri E. Associations between objectively measured physical activity and later mental health outcomes in children: findings from the UK Millennium Cohort Study. J Epidemiol Community Health. 2018;72:94-100. doi:10.1136/jech-2017-209455.

8. Akimoto M, Sekine M, Yamada M, Tatuse T. Factors relating to the feeling of school avoidance among elementary school children: Result from the MEXT (Ministry of Education, Culture, Sports, Science and Education) Super Shokuiku School Project. Nihon Koshu Eisei Zasshi. 2017;64(6):311321. (in Japanese) 
9. Sekine M, Yamagami T, Kagamimori S. Lifestyle and childhood obesity: Result from the Toyama Birth Cohort Study. Nihon Shoni Junkanki Gakkai Zasshi. 2008;24(5):589-597. (in Japanese)

10. Yamada M, Sekine M, Tatsuse T. Parental internet use and lifestyle factors as correlates of prolonged screen time of children in Japan: Result from the Super Shokuiku School Project. J Epidemiol. 2018;28(10):407-413. https://doi.org/10.2188/jea.JE20170100.

11. Tenjin K, Sekine M, Yamada M, Tatsuse T. Relationship between parental lifestyle and dietary habits of children: a cross-sectional study. J Epidemiol. 2019. doi:10.2188/jea.JE20190015.

12. Wiles NJ, Jones GT, Haase AM, Lawlor DA, Macfarlane GJ, Lewis G. Physical Activity and emotional problems amongst adolescents: A longitudinal study. Soc Psychiatry Psychiatr Epidemiol. 2008;43(10):765-772. doi:10.1007/s00127-008-0362-9.

13. Japan Sports Agency. Deportare. What are the challenges in children's exercise habits- Report on good examples of "physical education" to improve "bipolarization"! https://sports.go.jp/special/case/childrens-habit-of-physical-activity.html; Accessed 27 Jul 2019. (in Japanese)

14. Sekine M. Inequality society and children's lifestyle habits, educational opportunities, health, Protecting children from the chain of inequalities through social bonds. Gakujyutu no doukou. 2010;82-87. https://www.jstage.jst.go.jp/article/tits/15/4/15_4_4_82/_article/-char/ja/; Accessed 13 Jul 2019. (in Japanese)

15. UNICEF Office of Research. Innocenti Report Card 11: Child well-being in rich countries: A comparative overview. https://www.unicef-irc.org/publications/683-child-well-being-in-rich-countriesa-comparative-overview.html; Accessed 13 Jul 2019.

16. Moraeus L, Lissner L, Olsson L, Sjöberg A. Age and time effects on children's lifestyle and overweight in Sweden. BMC Public Health. 2015;15:355. doi: 10.1186/s12889-015-1635-3.

17. Hardy LL, Grunseit A, Khambalia A, Bell C, Wolfenden L, Milat AJ. Co-occurrence of obesogenic risk factors among adolescents. J Adolesc Health. 2012;51:265-271. doi:10.1016/j.

18. Liu J, Sekine M, Tatsuse T, Fujimura Y, Hamanishi S, Lu F, Zheng X. Outdoor physical activity and its relation with self-reported health in Japanese children: Results from the Toyama Birth Cohort Study. Child Care Health and Development. 2015;41(6): 920-927. doi:10.1111/cch.12262.

19. Chen X, Sekine M, Hamanishi S, Wang H, Gaina A, Yamagami T, Kagamimori S. Lifestyle and healthrelated quality of life in Japanese school children: A cross-sectional study. Preventive Medicine. 2005;40:668-678. doi: 10.1016/j.ypmed.2004.09.034

20. Yamada M, Sekine M, Tatsuse T, Asaka Y. Association between lifestyle, parental smoke, socioeconomic status, and academic performance in Japanese elementary school children: The Super Diet Education Project. Environ Health Prev Med. 2019; 9;24(1):22. doi:10.1186/s12199-0190776-x.

21. Chen X, Sekine M, Hamanishi S, Wang H, Gaina A, Yamagami T, Kagamimori S. Validation of a selfreported physical activity questionnaire for schoolchildren. J Epidemiol. 2003:13(5):278-287. doi:10.2188/jea.13.278. 
22. Nakahori N, Sekine M, Yamada M, Tatsuse T. The relationship between home environment and children's dietary behaviors, lifestyle factors, and health: Super Food Education School Project by the Japanese Ministry of Education, Culture, Sports, Science and Technology. Nihon Koshu Eisei Zasshi, 2016;63(4):190-201. (in Japanese)

23. Gaina A, Sekine M, Chen X, Hamanishi S, Kagamimori S. Sleep parameters recorded by Actiwatch in elementary school children and junior high school adolescent: schooldays vs weekends. Sleep Hypn. 2004;655-666.

24. Yamada M, Sekine M, Tatsuse T. Psychological stress, family environment, and constipation in Japanese children: The Toyama Birth Cohort Study. J Epidemiol. 2019;5;29(6):220-226. doi:10.2188/jea.JE20180016.

25. Nihon Kodomo Katei Sougoukennkyuusyo. Almanac of data on Japanese children 2016. Tokyo, Japan: KTC chuoshuppann (in Japanese).

26. Breslow L, Enstrom JE. Persistence of health habits and their relationship to mortality. Prev Med. 1980;9(4):469-483. doi:10.1016/0091-7435(80)90042-0.

27. Li W, Sekine M, Yamada M, Fujimura Y, Tatsuse T. Lifestyle and overall health in high school children: results from the Toyama Birth Cohort Study, Japan. Pediatr Int. 2018;60:467-473. doi:10.1111/ped.13548.

28. COOP/Wonca Charts, English Version. http://www.ph3c.org/4daction/w3_CatVisu/en/the-coop-/wonca-charts.html?wDoclD=150; Accessed 11 Sep 2019.

29. University of Toyama, Department of Epidemiology and Health Policy. The school avoidance feelings of fourth grade children. http://www.med.u-toyama.ac.jp/healpro/toyamast/sub6.html; Accessed 13 Jul 2019. (in Japanese)

30. Ward SA, Bélanger MF, Donovan D, Carrier N. Relationship between eating behaviors and physical activity of preschoolers and their peers: A systematic review. Int J Behav Nutr Phys Act. 2016;13:50. doi:10.1186/s12966-016-0374-x.

31. Initial findings from the Millennium Cohort Study Age 14 Survey. Mental ill-health and wellbeing at age 14. UCL. https://www.researchgate.net/publication/325264759_Mental_illhealth_and_wellbeing_at_age_14__Initial_findings_from_the_Millennium_Cohort_Study_Age_14_Survey; Accessed 13 Jul 2019.

32. World Health Organization. Gaming disorders. https://www.who.int/features/qa/gamingdisorder/en/; Accessed 05 Sep 2019.

33. Higuchi S. How do you protect children from "net dependency" that erodes the mind and body? Kyoto, Japan: Minerva; 2017. (in Japanese)

34. Takahashi T. Making friends by the challenge movement: "Karadahogushi no undou" that can be fun. Tokyo, Japan: Taishukanshoten; 2000. (in Japanese)

35. Goisis A, Sacker A, Kelly Y. Why are poorer children at higher risk of obesity and overweight? A UK Cohort Study. Eur J Public Health. 2016;26(1):7-13. doi:10.1093/eurpub/ckv219. 
36. Shimada K, Kasaba R, Yao A, Tomoda A. Less efficient detection of positive facial expressions in parents at risk of engaging in child physical abuse. BMC Psychol. 2019;7:56. doi:10.1186/s40359019-0333-9.

37. Fukushi T. Development and current issues of after-school child sound upbringing services. Research and legislative reference bureau National Diet Library. 2016. (in Japanese)

38. The Japan Research Institute, Limited. Research on comprehensive way of after school children's measures. 2018.

https://www.jri.co.jp/MediaLibrary/file/column/opinion/pdf/20180410_3_ashizawa.pdf; Accessed 13 Jul 2019. (in Japanese)

39. UNICEF Innocenti Research Centre Report Card 7. An overview of child well-being in rich countries. https://www.unicef-irc.org/publications/pdf/rc7_eng.pdf; Accessed 13 Jul 2019.

\section{Tables}

Table 1. Participant characteristics $(n=1,984)$ 


\begin{tabular}{|c|c|c|c|}
\hline \multicolumn{2}{|l|}{ Variable } & \multicolumn{2}{|l|}{$\mathbf{n}$} \\
\hline Sex & Boys & 1,001 & 50.5 \\
\hline Grade & $\begin{array}{l}\text { Girls } \\
\text { Low }\end{array}$ & $\begin{array}{l}983 \\
657\end{array}$ & $\begin{array}{l}49.5 \\
33.1\end{array}$ \\
\hline \multirow{4}{*}{$\begin{array}{l}\text { Social background and parental lifestyles } \\
\text { Mother's employment status }\end{array}$} & Middle & 624 & 31.5 \\
\hline & High & 702 & 35.4 \\
\hline & Full time & 804 & 41.5 \\
\hline & Part time & 871 & 44.9 \\
\hline Family structure & $\begin{array}{l}\text { Unemployed (housewife) } \\
\text { 3-generation family }\end{array}$ & $\begin{array}{l}264 \\
635\end{array}$ & $\begin{array}{l}13.6 \\
32.3\end{array}$ \\
\hline \multirow[t]{2}{*}{ Perceived Family Affluence } & $\begin{array}{l}\text { Nuclear family } \\
\text { Affluent }\end{array}$ & $\begin{array}{r}1,331 \\
491\end{array}$ & $\begin{array}{l}67.7 \\
25.0\end{array}$ \\
\hline & Neither & 932 & 47.5 \\
\hline Communication with parents & $\begin{array}{l}\text { No Affluent } \\
\text { Often }\end{array}$ & $\begin{array}{r}540 \\
1,608\end{array}$ & $\begin{array}{l}27.5 \\
81.8\end{array}$ \\
\hline Father's IU at home, h/day & $\begin{array}{l}\text { Rarely } \\
<2 \text { h }\end{array}$ & $\begin{array}{r}357 \\
1,553\end{array}$ & $\begin{array}{l}18.2 \\
85.8\end{array}$ \\
\hline Mother's IU at home, h/day & $\begin{array}{l}\geqq 2 h \\
<2 h\end{array}$ & $\begin{array}{r}256 \\
1,835\end{array}$ & $\begin{array}{l}14.2 \\
94.4\end{array}$ \\
\hline Father's health behaviors in Breslow's & $\geqq 2 \mathrm{~h}$ & $\begin{array}{l}109 \\
390\end{array}$ & $\begin{array}{r}5.6 \\
19.6\end{array}$ \\
\hline \multirow{4}{*}{ Mother's health behaviors in Breslow's } & Middle $\llbracket 4,5 \square$ & 771 & 38.8 \\
\hline & $\begin{array}{l}\text { Low } \square 0-3 \square \\
\text { High } \square 6,7 \square\end{array}$ & $\begin{array}{l}825 \\
506\end{array}$ & $\begin{array}{l}41.5 \\
25.5\end{array}$ \\
\hline & Middle $\llbracket 4,5 \square$ & 1,043 & 52.5 \\
\hline & Low $00-3 \square$ & 437 & 22.0 \\
\hline Breakfast eating & Every day & 1,817 & 92.0 \\
\hline Sleep duration & $\begin{array}{l}\text { Skipping } \\
\text { More than } 8 \text { hours }\end{array}$ & $\begin{array}{r}159 \\
1,539\end{array}$ & $\begin{array}{r}8.0 \\
78.5\end{array}$ \\
\hline Preference for physical activity & $\begin{array}{l}\text { Less than } 8 \text { hours } \\
\text { Like very much }\end{array}$ & $\begin{array}{r}422 \\
1,709\end{array}$ & $\begin{array}{l}21.5 \\
86.8\end{array}$ \\
\hline Frequency of physical activity & $\begin{array}{l}\text { Dislike } \\
\text { Very often }\end{array}$ & $\begin{array}{r}260 \\
1,430\end{array}$ & $\begin{array}{l}13.2 \\
72.6\end{array}$ \\
\hline Children's ST, h/day & $\begin{array}{l}\text { Not often } \\
<2 \mathrm{~h}\end{array}$ & $\begin{array}{r}540 \\
1,174\end{array}$ & $\begin{array}{l}27.4 \\
59.3\end{array}$ \\
\hline Cram schools & $\geqq 2 \mathrm{~h}$ & $\begin{array}{l}805 \\
372\end{array}$ & $\begin{array}{l}40.7 \\
18.9\end{array}$ \\
\hline
\end{tabular}




\begin{tabular}{llrr} 
& 1 times / week & 104 & 5.3 \\
Children's health & 0 time & 1495 & 75.8 \\
Overall health & Good & 1,824 & 92.6 \\
& Poor & 146 & 7.4 \\
$\begin{array}{c}\text { Enrichment of school life } \\
\text { Have close friends }\end{array}$ & Yes & 1,914 & 97.3 \\
& No & 54 & 2.7 \\
Understand the school study & Understand well & 1,575 & 80.2 \\
& Not understand & 390 & 19.8 \\
\hline
\end{tabular}

Table 2. Logistic regression analysis results for "Don't like physical activity" $(n=1,984)$ 
Variable Don't like physical activity $\quad$ Univariate Multivariate

\begin{tabular}{|c|c|c|c|c|}
\hline & & & $\begin{array}{c}\text { OR } \\
(95 \% \mathrm{CI}) \\
\end{array}$ & $\begin{array}{c}\text { OR } \\
(95 \% \mathrm{CI}) \\
\end{array}$ \\
\hline Sex & Boys & 12.8 & 1 & 1 \\
\hline \multirow{5}{*}{ Grade } & Girls & 13.6 & $1.07(0.83-$ & $1.25(0.93-$ \\
\hline & Low (1st-2nd) & 7.2 & 1 & 1 \\
\hline & Middle(3rd-4th) & 15.2 & \multirow{2}{*}{$\begin{array}{l}2.30(1.59- \\
3.33) \ddagger\end{array}$} & \multirow{2}{*}{$\begin{array}{l}2.39(1.59- \\
3.58) \neq\end{array}$} \\
\hline & $\operatorname{High}(5$ th-6th) & 17.1 & & \\
\hline & & & $\begin{array}{l}2.66(1.86- \\
3.80) \neq\end{array}$ & $\begin{array}{l}2.73(1.83- \\
4.08) \neq\end{array}$ \\
\hline \multicolumn{5}{|c|}{ Social background and parental lifestyles } \\
\hline Mother's employment & Full time & 13.0 & 1 & 1 \\
\hline \multirow[t]{3}{*}{ status } & Part time & 12.8 & \multirow{2}{*}{$\begin{array}{l}0.98(0.74- \\
1.31)\end{array}$} & \multirow{2}{*}{$\begin{array}{l}0.91(0.66- \\
1.24)\end{array}$} \\
\hline & \multirow[t]{2}{*}{ Unemployed(housewife) } & \multirow[t]{2}{*}{16.0} & & \\
\hline & & & $\begin{array}{l}1.72(0.86- \\
1.88)\end{array}$ & $\begin{array}{l}1.33(0.86- \\
2.06)\end{array}$ \\
\hline \multirow{2}{*}{ Family structure } & s-yenter a Livil Laniny & 14.0 & & \\
\hline & Nuclear family & 12.9 & \multirow{2}{*}{$\begin{array}{l}0.97(0.69- \\
1.20) \\
\quad 1\end{array}$} & \multirow{2}{*}{$\begin{array}{l}0.88(0.65- \\
1.19) \\
\quad 1\end{array}$} \\
\hline Perceived Family & Affluent & 12.7 & & \\
\hline \multirow[t]{3}{*}{ Affluence } & Neither & 12.6 & \multirow{2}{*}{$\begin{array}{l}0.99(0.71- \\
1.38)\end{array}$} & \multirow{2}{*}{$\begin{array}{l}1.11(0.77- \\
1.59)\end{array}$} \\
\hline & \multirow[t]{2}{*}{ No Affluent } & \multirow[t]{2}{*}{14.6} & & \\
\hline & & & $\begin{array}{l}1.18\left(0.82^{-}\right. \\
1.68)\end{array}$ & $\begin{array}{l}1.21(0.81- \\
1.82)\end{array}$ \\
\hline \multirow[t]{2}{*}{ Communication with parents } & Often & 12.1 & & 1 \\
\hline & Rarely & 18.5 & \multirow{2}{*}{$\begin{array}{c}1.65(1.22- \\
2.24) \ddagger \\
1\end{array}$} & \multirow{2}{*}{$\begin{array}{l}1.57(1.10- \\
2.25) * \\
1\end{array}$} \\
\hline Father's IU at home, & $<2 \mathrm{~h}$ & 13.5 & & \\
\hline h/day & $\geqq 2 \mathrm{~h}$ & 13.7 & \multirow{2}{*}{$\begin{array}{l}1.01(0.69- \\
1.49)_{1}\end{array}$} & \multirow{2}{*}{$\begin{array}{l}0.89(0.58- \\
1.36) \\
1\end{array}$} \\
\hline \multirow{2}{*}{$\begin{array}{l}\text { Mother's IU at home, } \\
\text { h/day }\end{array}$} & $<2 \mathrm{~h}$ & 13.1 & & \\
\hline & $\geqq 2 \mathrm{~h}$ & 15.7 & \multirow{2}{*}{$\begin{array}{l}1.24(0.72- \\
2.11)_{1}\end{array}$} & \multirow{2}{*}{$\begin{array}{l}1.02(0.55- \\
1.90) \\
1\end{array}$} \\
\hline \multirow{4}{*}{$\begin{array}{l}\text { Father's health behaviors in } \\
\text { Breslow's }\end{array}$} & High $\square 6,7 \square$ & 11.3 & & \\
\hline & Middle $\llbracket 4,5 \square$ & 13.3 & \multirow{2}{*}{$\begin{array}{l}0.79(0.54- \\
1.14)\end{array}$} & \multirow{2}{*}{$\begin{array}{l}1.04(0.69- \\
1.56)\end{array}$} \\
\hline & Low $\square 0-3 \square$ & 14.0 & & \\
\hline & & & $\begin{array}{l}0.95(0.71- \\
1.26)\end{array}$ & $\begin{array}{l}1.24(0.81- \\
1.91)\end{array}$ \\
\hline \multirow{3}{*}{$\begin{array}{l}\text { Mother's health behaviors in } \\
\text { Breslow's }\end{array}$} & $\operatorname{High} \square 6,7 \square$ & 10.7 & 1 & 1 \\
\hline & Middle $\llbracket 4,5 \square$ & 14.1 & $\begin{array}{l}1.36(0.98- \\
1.90)\end{array}$ & $\begin{array}{l}1.33(0.92- \\
1.92)\end{array}$ \\
\hline & Low $\square 0-3 \square$ & 14.0 & $\begin{array}{l}1.35(0.91- \\
2.00)\end{array}$ & $\begin{array}{l}1.25(0.79- \\
2.01)\end{array}$ \\
\hline
\end{tabular}




\section{Child lifestyle factors}

Breakfast eating

Sleep duration

Children's ST,

h/day

Cram schools

Children's health

Overall health

Enrichment of school life

Have close friends

Understand the

school study
Every day

Skipping

More than 8 hours

Less than 8 hours

$<2 \mathrm{~h}$

$\geqq 2 \mathrm{~h}$

$\geqq 2$ times / week

1 times / week

0 time

Good

Poor

Yes

No

Understand well

Not understand
13.4

10.9

$0.79(0.47-$ 1.33)

$12.2 \quad 1$

$0.60(0.33$ 1.07) 1

$17.1 \quad 1.49(1.11-\quad 1.33(0.96-$

$\begin{array}{lc}11.0 & 2.00) \dagger \\ 1\end{array}$

1.86)

16.3 1.57(1.21- 1.38(1.02-

$11.6 \begin{array}{cr}2.04) \ddagger & 1.87) * \\ 1 & 1\end{array}$

$13.5 \quad 1.19(0.62-\quad 1.09(0.52-$

13.6 2.27)

2.27)

$1.20(0.84-1.24(0.84-$ $1.70)$

1.82)

$\begin{array}{lll}12.6 & 1 & 1\end{array}$

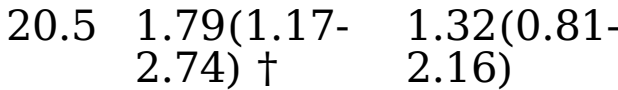

$\begin{array}{lll}12.2 & 1 & 1\end{array}$

48.1 6.66(3.84- 5.30(2.78-

$12.7 \begin{array}{lrr}11.6) \neq & 10.1) \neq\end{array}$

$15.41 .25(0.91-1.08(0.76-$ $1.71)$

OR, odds ratio; 95\%CI, 95\% confidence interval; IU, Internet use; ST, Screen time

$* p<0.05, \dagger p<0.01, \ddagger p<0.001$.

Table 3. Logistic regression analysis results for "Lack of physical activity" ( $n=1,984)$ 
Univariate Multivariate

\begin{tabular}{|c|c|c|c|c|}
\hline & & & $\begin{array}{c}\text { OR } \\
(95 \% \mathrm{CI})\end{array}$ & $\begin{array}{c}\text { OR } \\
(95 \% \mathrm{CI})\end{array}$ \\
\hline Sex & Boys & 25.6 & 1 & 1 \\
\hline \multirow{3}{*}{ Grade } & Girls & 29.2 & \multirow{2}{*}{$\begin{array}{c}1.20(0.99- \\
1.46) \\
1\end{array}$} & \multirow{2}{*}{$\begin{array}{c}1.40(1.11- \\
1.76) \dagger \\
1\end{array}$} \\
\hline & Low (1st-2nd) & 21.3 & & \\
\hline & Middle(3rd-4th) & 28.6 & \multirow{2}{*}{$\begin{array}{l}1.48(1.15- \\
1.91) \dagger\end{array}$} & \multirow{2}{*}{$\begin{array}{l}1.53(1.15- \\
2.04) \dagger\end{array}$} \\
\hline & $\operatorname{High}$ (5th-6th) & 31.9 & & \\
\hline & & & $\begin{array}{l}1.74(1.36- \\
2.22) \ddagger\end{array}$ & $\begin{array}{l}1.82(1.37- \\
2.42) \ddagger\end{array}$ \\
\hline \multirow[t]{3}{*}{ Mother's employment status } & $\begin{array}{l}\text { festyles } \\
\text { Full time }\end{array}$ & 24.1 & 1 & 1 \\
\hline & Part time & 27.5 & \multirow{2}{*}{$\begin{array}{l}1.20(0.96- \\
1.49)\end{array}$} & \multirow{2}{*}{$\begin{array}{l}1.18(0.92- \\
1.51)\end{array}$} \\
\hline & Unemployed(housewife) & 37.0 & & \\
\hline \multirow[t]{2}{*}{ Family structure } & 3-generation family & 27.6 & $\begin{array}{c}1.80(1.38- \\
2.50) \ddagger \\
1\end{array}$ & $\begin{array}{c}1.92(1.38- \\
2.68) \stackrel{\neq}{1} \\
1\end{array}$ \\
\hline & Nuclear family & 27.2 & \multirow{2}{*}{$\begin{array}{l}0.98(0.79- \\
1.21) \\
1\end{array}$} & \multirow{2}{*}{$\begin{array}{l}0.95(0.75 \\
1.20) \\
1\end{array}$} \\
\hline Perceived Family & Affluent & 25.8 & & \\
\hline \multirow[t]{2}{*}{ Affluence } & Neither & 27.4 & \multirow{2}{*}{$\begin{array}{l}1.08(0.85- \\
1.39)\end{array}$} & \multirow{2}{*}{$\begin{array}{l}1.06(0.81 \\
1.39)\end{array}$} \\
\hline & No Affluent & 28.2 & & \\
\hline \multirow[t]{2}{*}{ Communication with parents } & Often & 25.8 & ${ }_{1}^{1.49)}$ & ${ }^{1.27)} 1$ \\
\hline & Rarely & 35.0 & \multirow{2}{*}{$\begin{array}{c}1.55(1.21- \\
1.98) \neq \\
1\end{array}$} & \multirow{2}{*}{$\begin{array}{l}1.59(1.19- \\
2.13) \dagger \\
1\end{array}$} \\
\hline Father's IU at home, & $<2 \mathrm{~h}$ & 27.0 & & \\
\hline $\mathrm{h} /$ day & $\geqq 2 h$ & 31.6 & \multirow{2}{*}{$\begin{array}{c}1.25(0.94- \\
1.67)_{1}\end{array}$} & \multirow{2}{*}{$\begin{array}{c}1.06(0.77 \\
1.46) \\
1\end{array}$} \\
\hline Mother's IU at home, & $<2 \mathrm{~h}$ & 26.8 & & \\
\hline h/day & $\geqq 2 \mathrm{~h}$ & 37.0 & \multirow{2}{*}{$\begin{array}{c}1.61(1.07- \\
2.41) * \\
1\end{array}$} & \multirow{2}{*}{$\begin{array}{l}1.38(0.87- \\
2.21) \\
1\end{array}$} \\
\hline \multirow{4}{*}{$\begin{array}{l}\text { Father's health behaviors in } \\
\text { Breslow's }\end{array}$} & High $\square 6,7 \square$ & 22.2 & & \\
\hline & Middle $\square 4,5 \square$ & 27.4 & \multirow{2}{*}{$\begin{array}{l}1.33(1.00- \\
1.77)\end{array}$} & \multirow{2}{*}{$\begin{array}{l}1.15(0.84- \\
1.58)\end{array}$} \\
\hline & Low $\square 0-3 \square$ & 29.9 & & \\
\hline & & & $\begin{array}{l}1.50(1.13- \\
1.99) \dagger\end{array}$ & $\begin{array}{l}1.28(0.92- \\
1.78)\end{array}$ \\
\hline \multirow{3}{*}{$\begin{array}{l}\text { Mother's health behaviors in } \\
\text { Breslow's }\end{array}$} & High $\square 6,7 \square$ & 20.5 & & 1 \\
\hline & Middle $\llbracket 4,5 \square$ & 29.4 & $\begin{array}{l}1.62(1.26- \\
2.09) \neq\end{array}$ & $\begin{array}{l}1.50(1.13 \\
1.99) \dagger\end{array}$ \\
\hline & Low $\square 0-3 \square$ & 30.6 & $\begin{array}{l}1.71(1.27- \\
2.31) \neq\end{array}$ & $\begin{array}{l}1.53(1.07- \\
2.20) *\end{array}$ \\
\hline
\end{tabular}


Child lifestyle factors

Breakfast eating

Sleep duration

Children's ST, h/day

Cram schools

\section{Children's health \\ Overall health}

\section{Enrichment of school life}

Have close friends

Understand the

school study
Every day

Skipping

More than 8 hours

Less than 8 hours

$<2 \mathrm{~h}$

$\geqq 2 \mathrm{~h}$

$\geqq 2$ times / week

1 times / week

0 time

Good

Poor

Yes

No

Understand well

Not understand
27.6

25.6

27.0

$0.90(0.62-$ 1.31)

29.5

23.4

1.13(0.891.43)

33.1 1.62(1.32-

26.6 1.97) $\neq$

24.0

$0.87(0.53-$ 1.45)

27.8

1.06(0.821.37)

26.1

1

$41.1 \quad 1.97(1.40$ 2.79) $\ddagger$

26.2

1

68.5 6.12(3.42-

26.3 11.0) $\ddagger$

$31.51 .29(1.01-$ $1.64) *$
1

$0.74(0.48-$

1.15)

1

1.03(0.78-

1.36)

1

1.47(1.17-

1.86) $\ddagger$

1

$0.78(0.44-$ 1.37)

0.97(0.731.29)

1

1.66(1.12$2.47) *$

1

$5.40(2.81-$ $10.4) \ddagger$ 1

$1.02(0.77-$ $1.36)$

OR, odds ratio; 95\%CI, 95\% confidence interval; IU, Internet use; ST, Screen time

$* p<0.05, \dagger p<0.01, \neq p<0.001$.

Table 4. Logistic regression analysis results for "Lack of physical activity" regardless of "Prefer physical activity" $(\mathrm{n}=1,709)$ 
Sex
Grade

\section{Boys}

Girls

Low (1st-2nd)

Middle(3rd-4th)

High(5th-6th)

\section{Social background and parental lifestyles}

Mother's employment status

Family structure

Perceived Family

Affluence

Communication with parents

Father's IU at home,

h/day

Mother's IU at home,

h/day

Father's health behaviors in Breslow's

Mother's health behaviors in Breslow's
Full time

Part time

Unemployed(housewife)

3-generation family

Nuclear family

Affluent

Neither

No Affluent

Often

Rarely

$<2 \mathrm{~h}$

$\geqq 2 \mathrm{~h}$

$<2 \mathrm{~h}$

$\geqq 2 \mathrm{~h}$

High $\square$, 7ם

Middle $\llbracket 4,5 \square$

Low $\square 0-3 \square$

High $\square 6,7 \square$

Middle $\llbracket 4,5 \square$

Low $\square 0-3 \square$

13.1
16.5
14.3
13.9
15.8

16.5

$1.33(1.03-$

$1.71)^{*}$

$1.52(1.13-$

2.04) $\dagger$

$1.08(0.78-$ 1.48)

$1.12(0.78-$ 1.59)

$1.30(0.96-$

1.76)

$1.33(0.94-$

1.88)

$\begin{array}{lll}11.7 & 1 & 1\end{array}$

$15.1 \quad 1.35(1.02-\quad 1.36(0.99-$ $1.81) * \quad 1.87)$

21.8

$2.26(1.55-$

3.27) $\neq$

14.0

1

$2.30(1.52-$

3.47) $\ddagger$

14.9

13.9

$1.06(0.81-$ 1.40)

15.3 1.12(0.82$1.54)$

14.0 $1.04(0.72-$ 1.48)

14.3 1

17.1 1.36(0.99$14.1{ }^{1.87)} 1$

$18.41 .39(0.97-$ $14.3 \quad 3_{1}^{1.97)}$

1.01(0.741.37) 1

$0.99(0.71-$ 1.39)

$0.72(0.48-$ 1.08) 1

$21.3 \quad 1.72(1.05-\quad 1.55(0.89-$ $11.3 \begin{array}{cr}2.81) * & 2.69) \\ 1 & \end{array}$

$14.5 \quad 1.37(0.94-\quad 1.17(0.78-$ 1.99) 1.75)

16.7 1.64(1.142.37) $\dagger$

$1.24(0.81-$ 1.89)

$\begin{array}{lll}10.3 & 1 & 1\end{array}$

$15.9 \quad 1.74(1.24-\quad 1.55(1.08-$ 17.2 2.43) $\neq \quad 2.24) *$ $\begin{array}{ll}1.91(1.30- & 1.57(0.99- \\ 2.81) \neq & 2.49)\end{array}$ 


\section{Child lifestyle factors}

Breakfast eating

Sleep duration

Children’s ST, h/day

Cram schools

Children's health

Overall health

\section{Enrichment of school life}

Have close friends

Understand the

school study
Every day

Skipping

More than 8 hours

Less than 8 hours

$<2 \mathrm{~h}$

$\geqq 2 \mathrm{~h}$

$\geqq 2$ times / week

1 times / week

0 time

Good

Poor

Yes

No

Understand well

Not understand
14.8

1

1

$\begin{array}{lll}15.4 & 1.01(0.64- & 1.01(0.60- \\ 15.3 & 1.61) & 1.71)\end{array}$

13.3

0.91(0.661.25)

12.7

1

17.7 1.60(1.24$2.07) \ddagger$

15.6

1

12.5

$0.79(0.41-$ 1.51)

14.7 0.96(0.701.32)

$14.1 \quad 1$

$21.21 .90(1.23-$ 2.92) $\dagger$

$0.86(0.59-$ 1.24)

1

\subsection{4(1.15-} 2.08) $\dagger$

1

$0.65(0.32-$ 1.34)

$0.80(0.57-$ 1.14)

\begin{tabular}{ccc}
14.1 & 1 & 1 \\
21.2 & $\begin{array}{l}1.90(1.23- \\
2.92) \dagger\end{array}$ & $\begin{array}{l}1.63(1.00- \\
2.68)\end{array}$ \\
14.6 & 1 & 1 \\
20.4 & $\begin{array}{c}3.25(1.50- \\
7.01) \dagger\end{array}$ & $\begin{array}{l}4.14(1.80- \\
9.51) \ddagger\end{array}$ \\
14.3 & 1 & 1 \\
16.4 & $\begin{array}{l}1.23(0.90- \\
1.67)\end{array}$ & $\begin{array}{l}0.91(0.63- \\
1.32)\end{array}$ \\
\hline
\end{tabular}

OR, odds ratio; 95\%CI, 95\% confidence interval; IU, Internet use; ST, Screen time

$* p<0.05, \dagger p<0.01, \neq p<0.001$. 